\title{
A COMPARATIVE STUDY OF LEVOBUPIVACAINE WITH CLONIDINE AND LEVOBUPIVACAINE WITH DEXMEDETOMIDINE IN THORACIC EPIDURAL BLOCK FOR LAPAROSCOPIC CHOLECYSTECTOMY
}

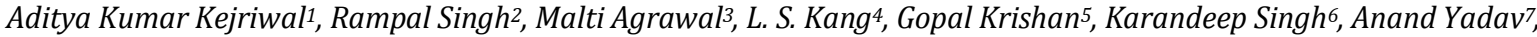 \\ Shaheen Begum ${ }^{8}$ \\ 13rd Year Junior Resident, Department of Anaesthesia, Rohilkhand Medical College \& Hospital, Bareilly, Uttar Pradesh. \\ ${ }^{2}$ Associate Professor, Department of Anaesthesia, Rohilkhand Medical College \& Hospital, Bareilly, Uttar Pradesh. \\ 3 Professor and HOD, Department of Anaesthesia, Rohilkhand Medical College \& Hospital, Bareilly, Uttar Pradesh. \\ ${ }^{4}$ Professor, Department of Anaesthesia, Rohilkhand Medical College \& Hospital, Bareilly, Uttar Pradesh. \\ ${ }_{5}^{5}$ Assistant Professor, Department of Anaesthesia, Rohilkhand Medical College \& Hospital, Bareilly, Uttar Pradesh. \\ ${ }^{6} 3^{\text {rd }}$ Year Junior Resident, Department of Anaesthesia, Rohilkhand Medical College \& Hospital, Bareilly, Uttar Pradesh.

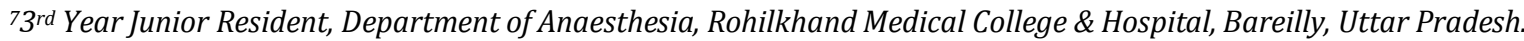 \\ ${ }^{8}$ Senior Resident, Department of Anaesthesia, Rohilkhand Medical College \& Hospital, Bareilly, Uttar Pradesh.
}

\section{ABSTRACT}

Laparoscopic cholecystectomy has traditionally been performed under general anaesthesia, regional anaesthetic techniques like spinal and epidural anaesthesia has emerged as a more suitable alternative for the minimally invasive laparoscopic cholecystectomy. We conducted a clinical study comparing levobupivacaine with clonidine and a combination of levobupivacaine with dexmedetomidine in thoracic epidural anaesthesia for laparoscopic cholecystectomy as sole anaesthetic.

\section{MATERIAL AND METHODS}

After taking approval from Institutional Ethical Committee, 100 adult patients of ASA grade I and II were divided into two groups; Group 1 where levobupivacaine $0.5 \%(2 \mathrm{mg} / \mathrm{kg}$ ) with $1.5 \mu \mathrm{g} / \mathrm{kg}$ clonidine was given and in Group 2 levobupivacaine $0.5 \%(2 \mathrm{mg} / \mathrm{kg})$ with $0.5 \mu \mathrm{g} / \mathrm{kg}$ of dexmedetomidine. Thoracic epidural was given at the $\mathrm{T}_{10}-\mathrm{T}_{11}$ interspace to obtain a sensory block of $\mathrm{T}_{4}-\mathrm{L}_{2}$ dermatome, which was judged every minute by pinprick method till complete sensory block was established. Hemodynamic parameters like heart rate, non-invasive blood pressure, electrocardiogram, oxygen saturation were monitored and readings were recorded initially then at every 5 mins after administration of drug intraoperatively.

\section{RESULT}

Duration of block was longer in group 2 patients, onset of block was comparable in both the groups. Also fall in blood pressure and heart rate was greater in group 2 patients. Less incidence of shoulder pain was found in group 2 patients. Oxygen saturation $\left(\mathrm{Spo}_{2}\right)$ was comparable in both the groups and no respiratory distress was seen. More post-operative analgesia was required in group 1. Also no complications were seen postoperatively in both the groups.

\section{CONCLUSION}

Levobupivacaine with dexmedetomidine provides better anaesthesia than levobupivacaine with clonidine in thoracic epidural for laparoscopic cholecystectomy.

\section{KEYWORDS}

Dexmedetomidine, Clonidine, Thoracic Epidural Anaesthesia, Laparoscopic Cholecystectomy.

HOW TO CITE THIS ARTICLE: Kejriwal AK, Singh R, Agrawal M, et al. A comparative study of levobupivacaine with clonidine and levobupivacaine with dexmedetomidine in thoracic epidural block for laparoscopic cholecystectomy. J. Evolution Med. Dent. Sci. 2016;5(14):615-619, DOI: 10.14260/jemds/2016/140

\section{INTRODUCTION}

Laparoscopic cholecystectomy is performed both under general anaesthesia and regional anaesthesia, regional anaesthetic techniques like spinal and epidural anaesthesia are implied now-a-days for laparoscopic cholecystectomy. We conducted a clinical study comparing levobupivacaine with clonidine and a combination of levobupivacaine with dexmedetomidine in thoracic epidural anaesthesia.

Financial or Other, Competing Interest: None.

Submission 02-01-2016, Peer Review 28-01-2016,

Acceptance 05-02-2016, Published 16-02-2016.

Corresponding Author:

Dr. Aditya Kumar Kejriwal,

Room No.-12, PG Boys Hostel,

Rohilkhand Medical College \& Hospital,

Bareilly-243006, Uttar Pradesh, India.

E-mail: adityakej@gmail.com

DOI: $10.14260 /$ jemds/2016/140
Epidural anaesthesia has many advantages over spinal anaesthesia, which include possibility of day care surgery with less chances of urinary retention.

Spinal anaesthesia is unable many times to achieve desired block level, also if block level becomes above T4, cardiac depression may occur.

Epidural anaesthesia has better titration of block level, so also preferred in patients with co-morbid conditions like COPD.

Pre-requisites for epidural anaesthesia are a cooperative patient and low Intra-Abdominal Pressure (IAP) to avoid problems like shoulder pain and ventilation disturbances.

With epidural anaesthesia patient is able to maintain their ventilation and adjust respiration owing to less chances of carbon-dioxide retention. 
Levobupivacaine is an isomer of bupivacaine and has emerged more beneficial due to its less cardio-toxic nature. Addition of clonidine or dexmedetomidine decreases the dose requirement of levobupivacaine and improves quality of block. Alpha-2 agonists like Clonidine and dexmedetomidine act on the sympathetic nervous system causing presynaptic inhibition in a negative feedback manner and improve quality of block and decrease dose requirement of main drug levobupivacaine. Dexmedetomidine is a highly selective $\alpha_{2}$ adrenergic agonist with an affinity of eight times greater than clonidine.

\section{MATERIAL AND METHODS}

After obtaining approval of ethical committee and informed written consent, 100 ASA grade I and II patients aged 18-60 years, of both sexes, scheduled for laparoscopic cholecystectomy under epidural anaesthesia were included in this study. Exclusion criteria were severe anaemia, COPD, heart disease, morbid obesity, altered liver function test, patient on anticoagulation, renal and endocrine diseases.

Pre-anaesthetic checkup was done a day before surgery, relevant investigations were done and informed written consent was taken. Patients were asked to remain nil per oral $8 \mathrm{hrs}$. before surgery. Patients were pre-medicated with tablet alprazolam $0.5 \mathrm{mg}$ and tab ranitidine $150 \mathrm{mg}$ in the night before surgery.

In OT a good IV access was secured and preloading done with $500 \mathrm{~mL}$ lactated Ringer's solution and a monitor was attached for monitoring ECG, HR, NIBP, SPO2, temperature, respiratory rate. Patient were made to sit with their elbows resting on their thighs on a bedside table. Flexion of the spine was done and midline approach was used for epidural.

After proper positioning and under strict aseptic precautions local infiltration with $2 \mathrm{~mL}$ of $2 \%$ lignocaine with adrenaline 1:200,000 was done at T10-T11 intervertebral space. Epidural block was given with 18-G Tuohy's needle (By the loss of resistance method with $10 \mathrm{~mL}$ L.O.R Syringe). A test dose of $3 \mathrm{~mL}$ of $2 \%$ lignocaine hydrochloride solution containing 1:200,000 adrenaline was injected and thereafter patients in group 1 received $2 \mathrm{mg} / \mathrm{kg} \mathrm{0.5 \%} \mathrm{L-bupivacaine} \mathrm{and}$ $1.5 \mu \mathrm{gm} / \mathrm{kg}$ of clonidine and patients in group 2 received $2 \mathrm{mg} / \mathrm{kg}, \quad 0.5 \% \quad$ L-bupivacaine and $0.5 \mu \mathrm{gm} / \mathrm{kg}$ of dexmedetomidine. Onset of action and level of sensory block was judged by pinprick method.

Each patient was monitored intraoperatively for heart rate, non-invasive blood pressure and arterial 02 saturation (Sp02). Intra-abdominal pressure was kept between 10$12 \mathrm{mmHg}$. Hypotension was defined as systolic blood pressure $<90 \mathrm{mmHg}$ or $>20 \%$ decrease from baseline values and was treated by fluids and vasopressors (Mephentermine 6mg). Bradycardia was defined as heart rate $<50 / \mathrm{min}$ and was treated by $0.6 \mathrm{mg}$ of atropine injection. Intraoperative nausea, vomiting, pruritus, sedation or any other side effects were recorded.

\section{STATISTICAL METHODS}

At the end of the study, the data was compiled systematically and analysed using statistical package for social sciences (SPSS) software. Chi-square test was used to compare the proportional data. Mean differences were compared using students $T$-test and a $P$ value $<0.05$ showed a significant intergroup difference.

\section{RESULTS}

There was no statistically significant difference between the two groups in any of the demographic data. At baseline, mean heart rate, diastolic blood pressure, systolic blood pressure were comparable between the two groups and were in normal ranges.

\begin{tabular}{|c|c|c|c|c|c|c|}
\hline \multirow{2}{*}{ Hemodynamic Variables } & \multicolumn{2}{|c|}{ Group 1 (n=50) } & \multicolumn{2}{c|}{ Group 2 (n=50) } & \multicolumn{2}{c|}{ Statistical Significance } \\
\cline { 2 - 7 } & Mean & SD & Mean & SD & 't' & 0.6293 \\
\hline Heart Rate (per min) & 88.34 & 15.12 & 90.6 & 14.24 & 0.487 & 0.4601 \\
\hline Diastolic BP (mmHg) & 64.42 & 11.01 & 66.6 & 11.69 & 0.7436 & 0.4816 \\
\hline Systolic BP (mmHg) & 126.55 & 18.72 & 130.02 & 11.24 & 0.711 & \\
\hline \multicolumn{7}{|r}{ Table 1: Baseline hemodynamic variables }
\end{tabular}

It was found that all the above hemodynamic variables (Heart rate, diastolic BP and Systolic BP) of Group 2 were found to be slightly higher than that of Group 1, but none of the difference was found to be statistically significant ( $p>0.05)$.

\begin{tabular}{|c|c|c|c|c|c|c|}
\hline \multirow{2}{*}{ Time Interval } & \multicolumn{2}{|c|}{ Group 1 } & \multicolumn{2}{c|}{ Group 2 } & \multicolumn{2}{c|}{ Statistical Significance } \\
\cline { 2 - 7 } & Mean & SD & Mean & SD & \multicolumn{1}{c|}{$\mathbf{t}^{\prime}$} & 0.4816 \\
\hline Baseline & 130.02 & 11.24 & 126.55 & 18.72 & 0.711 & 0.127 \\
\hline $5 \mathrm{~min}$ & 113.3 & 10.57 & 114.75 & 20.91 & 1.302 & 0.9421 \\
\hline $10 \mathrm{~min}$ & 108.6 & 12.78 & 108.45 & 18.06 & 0.078 & 0.2123 \\
\hline $15 \mathrm{~min}$ & 106.8 & 15.26 & 115.7 & 16.12 & 1.184 & 0.8642 \\
\hline $20 \mathrm{~min}$ & 110.5 & 13.84 & 121.3 & 26.86 & 0.346 & 0.368 \\
\hline $25 \mathrm{~min}$ & 109.3 & 9.44 & 115.05 & 16 & 0.905 & 0.365 \\
\hline $30 \mathrm{~min}$ & 112.7 & 6.89 & 117.25 & 13.73 & 0.911 & 0.1127 \\
\hline $35 \mathrm{~min}$ & 110 & 9.71 & 110.15 & 12.7 & 1.1623 & 0.2536 \\
\hline $40 \mathrm{~min}$ & 108.4 & 8.88 & 108.78 & 12.21 & 1.161 & 0.1008 \\
\hline $45 \mathrm{~min}$ & 108.1 & 7.9 & 110.46 & 10.11 & 1.67 & 0.7174 \\
\hline $50 \mathrm{~min}$ & 109.3 & 7.01 & 110 & 6.68 & 0.389 & 0.4186 \\
\hline $55 \mathrm{~min}$ & 104.9 & 6.78 & 106 & 4.32 & 0.819 & 0.303 \\
\hline $60 \mathrm{~min}$ \\
\hline
\end{tabular}

Systolic blood pressure of both the groups were comparable at all-time intervals 


\begin{tabular}{|c|c|c|c|c|c|c|}
\hline \multirow{2}{*}{ Time Interval } & \multicolumn{2}{|c|}{ Group 1} & \multicolumn{2}{|c|}{ Group 2} & \multicolumn{2}{|c|}{ Statistical Significance } \\
\hline & Mean & SD & Mean & SD & 't' & 'p' \\
\hline Baseline & 64.4 & 11.01 & 66.6 & 11.69 & 0.7436 & 0.4601 \\
\hline $5 \mathrm{~min}$ & 68.9 & 10.57 & 71.05 & 13.95 & 1.532 & 0.127 \\
\hline $10 \mathrm{~min}$ & 65.5 & 12.78 & 65.75 & 11.8 & 0.092 & 0.9151 \\
\hline $15 \mathrm{~min}$ & 65.7 & 15.26 & 72.2 & 15.75 & 1.147 & 0.2492 \\
\hline $20 \mathrm{~min}$ & 71 & 13.84 & 75.6 & 16.78 & 0.252 & 0.8231 \\
\hline $25 \mathrm{~min}$ & 69.9 & 9.44 & 71.6 & 13.61 & 0.806 & 0.388 \\
\hline $30 \mathrm{~min}$ & 72.5 & 6.89 & 74.35 & 10.08 & 0.962 & 0.3858 \\
\hline $35 \mathrm{~min}$ & 70.5 & 9.71 & 70.5 & 11.32 & 1.1623 & 0.1127 \\
\hline $40 \mathrm{~min}$ & 68.5 & 8.88 & 68.15 & 8.82 & 1.181 & 0.2432 \\
\hline $45 \mathrm{~min}$ & 72 & 7.9 & 70.46 & 6.23 & 1.913 & 0.0653 \\
\hline $50 \mathrm{~min}$ & 69.1 & 7.01 & 70.01 & 5.99 & 0.389 & 0.7174 \\
\hline $55 \mathrm{~min}$ & 65.1 & 6.78 & 66.75 & 3.77 & 1.924 & 0.0911 \\
\hline $60 \mathrm{~min}$ & 66.9 & 6.74 & 62.5 & 9.19 & 1.813 & 0.0753 \\
\hline
\end{tabular}

Table 3: Intergroup Comparison of Diastolic Blood Pressure ( $\mathrm{mmHg}$ ) at different time intervals

Diastolic blood pressure of both the groups were comparable at all-time intervals

\begin{tabular}{|c|c|c|c|c|c|c|}
\hline \multirow{2}{*}{ Time Interval } & \multicolumn{2}{|c|}{ Group 1} & \multicolumn{2}{|c|}{ Group 2} & \multicolumn{2}{|c|}{ Statistical Significance } \\
\hline & Mean & SD & Mean & SD & 't' & 'p' \\
\hline Baseline & 88.3 & 15.12 & 90.6 & 14.24 & 0.487 & 0.6293 \\
\hline $5 \min$ & 88.1 & 13.05 & 88.2 & 13.12 & 1.502 & 0.137 \\
\hline $10 \mathrm{~min}$ & 86.6 & 14.17 & 83.7 & 14.27 & 0.082 & 0.9351 \\
\hline $15 \mathrm{~min}$ & 82 & 17.95 & 78.45 & 20.54 & 1.137 & 0.259 \\
\hline $20 \mathrm{~min}$ & 84.3 & 18.8 & 80.85 & 18.29 & 0.222 & 0.8246 \\
\hline $25 \mathrm{~min}$ & 81.3 & 17.83 & 76.65 & 17.61 & 0.905 & 0.368 \\
\hline $30 \mathrm{~min}$ & 82.2 & 17.14 & 77.8 & 17.77 & 0.911 & 0.365 \\
\hline $35 \mathrm{~min}$ & 81.6 & 16.12 & 75.65 & 16.95 & 1.2 & 0.2344 \\
\hline $40 \mathrm{~min}$ & 76.8 & 14.73 & 72.1 & 12.74 & 1.622 & 0.1095 \\
\hline $45 \mathrm{~min}$ & 72.7 & 9.42 & 73.23 & 11.17 & 1.927 & 0.0082 \\
\hline $50 \mathrm{~min}$ & 74.5 & 9.67 & 76.85 & 10.17 & 1.1623 & 0.1127 \\
\hline $55 \mathrm{~min}$ & 76.6 & 16.23 & 80.75 & 15.9 & 1.161 & 0.2536 \\
\hline $60 \mathrm{~min}$ & 72.5 & 11.61 & 74.5 & 4.94 & 1.913 & 0.0653 \\
\hline
\end{tabular}

Heart rate in both the groups were comparable at all-time intervals

\begin{tabular}{|c|c|c|}
\hline Injection & Group 1 & Group 2 \\
\hline 1injection & $15(30 \%)$ & $20(40 \%)$ \\
\hline 2injection & $25(50 \%)$ & $30(60 \%)$ \\
\hline 3injection & $10(20 \%)$ & 0 \\
\hline \multicolumn{3}{|c|}{ Table 5: Post-op analgesia (Diclofenac 75mg } \\
intramuscular) required in Group 1 and Group 2 \\
\hline
\end{tabular}

Group 2 had significantly lower rescue analgesic need as compared to Group 1.

Mean heart rates of two groups were comparable throughout the procedure and did not show a statistically significant difference $(p>0.05)$. Mean diastolic blood pressures of two groups were comparable throughout the procedure and did not show a statistically significant difference at all time intervals $(p>0.05)$. Mean systolic blood pressures of two groups were comparable throughout the study ( $p>0.05)$. In both the groups at all intervals mean heart rate, systolic blood pressures and diastolic blood pressures were significantly lower as compared to baseline $(\mathrm{p}<0.05)$.

Mean onset time of sensory block was $8.82 \pm 2.74$ minutes in Group 1 and $8.45 \pm 2.56$ minutes in Group 2, thus showing a faster onset of block in Group 2, but mean onset time of sensory block were statistically comparable ( $p>0.05)$.
Mean duration of sensory block was $4.87 \pm 0.79$ hours in Group 1 and 5.74 \pm 1.53 hours in Group 2, thus showing a longer duration of block in group $2(\mathrm{p}<0.05)$.

Vasopressor requirement was significantly higher in Group $2(20 \%)$ as compared to Group $1(16 \%)(\mathrm{p}<0.05)$. Ketamine requirement for shoulder pain was significantly higher in Group 1 (36\%) patients as compared to Group 2 $(24 \%)(p<0.05)$. Atropine requirement were comparable in both the groups ( $\mathrm{p}>0.05)$.

Muscle relaxation was judged as adequate by the surgeon in most of the cases at the end of surgery. None of the patients complained of nausea, vomiting, headache and dizziness postoperatively. Also, Group 2 had significantly lower rescue analgesic need as compared to Group $1(\mathrm{p}<0.05)$.

\section{DISCUSSION}

Regional anaesthesia is becoming very popular as compared to general anaesthesia for patient undergoing upper abdominal surgery, especially laparoscopic surgeries owing to their ability to provide good and superior intra-operative as well as post-operative analgesia. There are less side effects as compared to general anaesthesia and patient does not suffer from the problems associated with general anaesthesia, especially during intraoperative period and reversal time. 
Patients are awake and oriented at the end of the surgery and have less postoperative pain, urinary retention, nausea and vomiting. Problems related to general anaesthesia such as oral and dental injury during laryngoscopy, stomach inflation as a result of mask ventilation and sore throat as a result of intubation might be avoided in a regional anaesthesia setting.

Epidural anaesthesia is increasingly getting advocated for laparoscopic surgeries. Epidural anaesthesia reduces morbidity, mortality, length of hospital stay and costs when compared with general anaesthesia. Epidural anaesthesia also reduces intraoperative blood loss and the need for blood transfusions.[1]

Ventilation is maintained in epidural anaesthesia as well as there is no marked increase in end-tidal carbon-dioxide levels in laparoscopic procedures.[2-3]

For laparoscopic procedures intra-abdominal pressures should be kept optimally low if done under epidural anaesthesia.[4] We kept intra-abdominal pressure between 10 $12 \mathrm{mmHg}$ and preferably a sensory block of T4-L2 is required.[5] Also using epidural anaesthesia alone as a sole anaesthetic technique for laparoscopic surgery does not guarantee complete relief from shoulder pain, which is caused due to irritation of diaphragm.[5]

Classically, Bupivacaine is used for epidural anaesthesia in laparoscopic procedures.[5] Its congener levobupivacaine is less cardiotoxic and is frequently being used now-a-days. Also adjuvants like fentanyl, clonidine and dexmedetomidine prolong the action of main anaesthetic agent and block levels are reached quickly.[5]

We studied two anaesthetic adjuvants, i.e. clonidine and dexmedetomidine with levobupivacaine in thoracic epidural block for laparoscopic cholecystectomy.

For this purpose a double-blinded prospective randomized controlled study was carried out in which a total of 100 patients belonging to ASA grade 1 or 2 undergoing laparoscopic cholecystectomy procedure were enrolled and were randomly allocated to one of the two groups. A total of 50 patients in Group 1 received epidural anaesthesia with 0.5\% $(2 \mathrm{mg} / \mathrm{kg})$ levobupivacaine with $1.5 \mu \mathrm{g} / \mathrm{kg}$ clonidine, while remaining 50 patients in Group 2 received epidural anaesthesia with $0.5 \%(2 \mathrm{mg} / \mathrm{kg})$ levobupivacaine with $0.5 \mu \mathrm{g} / \mathrm{kg}$ dexmedetomidine.

At baseline both the groups were comparable hemodynamically. Throughout the procedure, statistically no significant difference between two groups was observed with respect to hemodynamic parameters.

In both the groups, mean heart rate and blood pressure levels were either significantly lower or comparable to the baseline levels.[5-8] Mean onset time of sensory block was $8.82 \pm 2.74$ minutes and mean duration of sensory block was $4.87 \pm 0.79$ hours in Group 1.[9]

Mean onset time of sensory block was $8.45 \pm 2.56$ minutes and mean duration of sensory block was $5.74 \pm 1.53$ hours in Group 2, Kamal et al. studied levobupivacaine with dexmedetomidine for thoracic epidural anaesthesia for major abdominal surgeries found that mean onset of sensory block as $12.6 \pm 5.9$ minutes and mean regression time of sensory block was $390 \pm 87.6$ mins, which was different from our study. This may be due to different doses of the drugs.[10] administered.

In present study, Group 2 had significantly lower rescue analgesic need as compared to Group 1, thus showing that levobupivacaine in combination with dexmedetomidine provided a better analgesic effect as compared to levobupivacaine in combination with clonidine. Bajwa et al. also compared dexmedetomidine and clonidine in epidural anaesthesia with ropivacaine and concluded the same results.[6]

Thoracic epidural anaesthesia for laparoscopic cholecystectomy is a satisfactory alternative technique in selected cases. Addition of clonidine $(2 \mu \mathrm{g} / \mathrm{kg})$ to bupivacaine produces better quality of block. It decreases hemodynamic changes produced by pneumoperitoneum and also decreases the incidence of shoulder pain.[5]

Ketamine $25 \mathrm{mg}$ was used for alleviating shoulder pain in 18 patients in group 1 and 12 patients in group 2 at a fixed dose of $25 \mathrm{mg}$. Incidence of shoulder pain is also proportional to the magnitude of intra-abdominal pressure.[4,5,11-12]

Although levobupivacaine is free from any cardiotoxic effects and has a similar safety profile, but hypotensive effect in both the groups was due to blockade of sympathetic system. Maintenance of blood pressure lower than the baseline is a preventive measure in laparoscopic cholecystectomy cases in order to tackle with the surgical stress response. However, hypotensive episodes were of considerable significance in both the groups. Clonidine had hypotensive effect, which sustained up to eight hours. Clonidine and related alpha-2 adrenergic receptor agonists lower arterial pressure primarily by an action within the central nervous system. ${ }^{[13-14]}$

Clonidine is lipophilic and as a result is quickly redistributed systemically despite neuraxial injection. It therefore has both central and peripheral effects. At lower doses, the central effects cause sympatholysis leading to hypotension, while the peripheral effects at higher doses cause vasoconstriction. Clonidine administered in the low thoracic or lumbar region typically produces blood pressure effects similar to that seen with intravenous administration.[13-14] When given in the mid or upper thoracic regions, epidurally administered clonidine causes an even greater decrease in blood pressure.[15] This more substantial drop in blood pressure is due to blocking thoracic sympathetic fibres.

Hypotension, defined as a fall in blood pressure by more than $20 \%$ of pre-anaesthetic value was managed by rapid crystalloid infusion and/or intravenous bolus of $6 \mathrm{mg}$ mephentermine. Bradycardia $(<50$ beats $/ \mathrm{min})$ was treated with IV $0.6 \mathrm{mg}$ atropine. In group 2, 10 patients required mephentermine, while in group 1,8 patients required mephentermine, although both dexmedetomidine and clonidine cause hypotension, but hypotension was more pronounced in dexmedetomidine group. As dexmedetomidine is a highly selective $\alpha_{2}$ adrenergic agonist with an affinity of eight times greater than clonidine. Two patients in each group required atropine.

Muscle relaxation was adequate and comparable in both the groups. The incidence of side effects like nausea, vomiting, headache, shivering and dizziness were comparable in both the groups and statistically non-significant. We did not observe the respiratory depression in any patient from either group.[6]

Our study showed that levobupivacaine in combination with dexmedetomidine has a better clinical profile than levobupivacaine in combination with clonidine when used in thoracic epidural block as the onset of block was comparably equal in both the groups, but duration of block was 
comparably longer in dexmedetomidine group.[6] Although vasopressor requirement was more in dexmedetomidine group, which may be due to more $\alpha^{2}$ specificity of dexmedetomidine. Post-operative analgesic requirement was more in clonidine group.[6]

\section{CONCLUSION}

Laparoscopic cholecystectomy can be easily performed under thoracic epidural block. Adjuvants like clonidine or dexmedetomidine added to levobupivacaine not only produces better quality of block. These drugs minimize hemodynamic changes produced by pneumoperitoneum and also decrease the incidence of shoulder pain. Based on our study, we recommend that dexmedetomidine is a better adjuvant than clonidine when used along with levobupivacaine in thoracic epidural anaesthesia for laparoscopic cholecystectomy.

\section{REFERENCES}

1. Rodgers A, Walker N, Schug S, et al. Reduction of postoperative mortality and morbidity with epidural or spinal anaesthesia: results from overview of randomised trials. BMJ 2000 Dec 16;321:1493-7.

2. Miller Ronald D. Miller's Anaesthesia, 7th ed. Philadelphia: Churchill Livingstone; 2010, P 2196.

3. Raju N Pusapati, Sivashanmugam T and Murugesan RS. Respiratory changes during spinal anaesthesia for gynaecological laparoscopic surgery. JOACP 10/2010;26(4):475-9.

4. Sarli L, Costi R, Sansebastiano G, et al. Prospective randomized trial of low-pressure pneumoperitoneum for reduction of shoulder tip pain following laparoscopy. Br J Surg 2000;87:1161-5.

5. Agrawal M, Verma AP and Kang LS. Thoracic epidural anaesthesia for laparoscopic cholecystectomy using either bupivacaine or a mixture of bupivacaine and clonidine: a comparative clinical study. Anaesth Essays Res 2013 Jan-Apr; 7(1):44-48.
6. Bajwa SJ, Bajwa SK, Kaur J, et al. Dexmedetomidine and clonidine in epidural anaesthesia: a comparative evaluation. Indian J Anaesth 2011;55:116-21.

7. Jaakola ML, Salonen M, Lehtinen R, et al. The analgesic action of dexmedetomidine-a novel alpha-2 adrenoceptor agonist-in healthy volunteers. Pain 1991 Sep;46(3):281-5.

8. Dexmedetomidine: Bhana N, Goa KL and McClellan KJ. Drugs 2000 Feb;59(2):263-8; discussion 269-70.

9. Pandey A, Kumar R, Kang LS, et al. Comparative study between levobupivacaine with clonidine and ropivacaine with clonidine in thoracic epidural block for laparoscopic cholecystectomy. JEMDS 2015;4(9):1457-1465.

10. Kamal MM and Talaat SM. Comparative study of epidural morphine and epidural dexmedetomidine used as adjuvant to levobupivacaine in major abdominal surgery. Egyptian Journal of Anaesthesia 2014;30:137-141.

11. Kar M, Kar JK, Debnath B. Experience of laparoscopic cholecystectomy under spinal anaesthesia with lowpressure pneumoperitoneum--prospective study of 300 cases. Saudi J Gastroenterol 2011;17:203-7.

12. Sinha R, Gurwara AK, Gupta SC. Laparoscopic cholecystectomy under spinal anaesthesia: a study of 3492 patients. J Laparoendosc Adv Surg Tech A 2009;19:323-7.

13. Guyenet PG. Is the hypotensive effect of clonidine and related drugs due to imidazoline binding sites? Am J Physiol 1997 Nov;273(5 Pt 2):R1580-4.

14. De Kock M, Crochet B, Morimont C, et al. Intravenous or epidural clonidine for intra- and postoperative analgesia. Anaesthesiology 1993;79(3):525-531.

15. De Kock M. Site of hemodynamic effects of alpha sub 2adrenergic agonists. Anaesthesiology 1991;75:715-716. 